\title{
Efeito da adição dietética de milho de alta qualidade protéica em camundongos
}

\author{
Effect of adding high-quality protein \\ maize to the diet of mice
}

\author{
Aline Castro SILVA' \\ Ricardo Ferreira MURADAS 1 \\ Éder Galinari FERREIRA ${ }^{1}$ \\ Déborah Kristina BRAGA ${ }^{1}$ \\ Flávia Márcia OLIVEIRA ${ }^{1}$ \\ Alexandre Sylvio Vieira da $\operatorname{COSTA}^{1}$
}

\section{R E S U M O}

\section{Objetivo}

O objetivo do estudo consistiu em avaliar os efeitos da adição de milho quality protein maize BR473 sobre aspectos bioquímicos e fisiológicos.

\section{Métodos}

Camundongos Swiss, fêmeas, 6-7 semanas, foram alimentados com rações comerciais, rações comerciais com milho híbrido (1:1), rações comerciais com milho de alta qualidade protéica (1:1). Foram avaliados, durante 3 meses, o consumo de ração, o ganho de peso e de tecido adiposo retroperitoneal e os valores plasmáticos de proteínas, triglicerídeos, colesterol e glicose.

\section{Resultados}

A adição dietética de milho quality protein maize BR473 reduziu o consumo alimentar e o tecido adiposo retroperitoneal, porém manteve a glicemia e trigliceridemia em relação à adição de milho híbrido na ração comercial.

\section{Conclusão}

A melhor eficiência alimentar e os impactos sobre os parâmetros bioquímicos do sangue sugerem o potencial do uso do milho quality protein maize BR473 como um importante complemento para garantir a segurança alimentar e nutricional.

Termos de indexação: consumo de alimentos; glicose; milho; triglicerídeos.

A B S T R A C T

\section{Objective}

The aim of this work was to evaluate the biochemical and physiological effects of adding quality protein maize BR473 to the diet of mice.

\footnotetext{
1 Centro Universitário do Leste de Minas Gerais, Departamento das Ciências da Saúde. R. Bárbara Heliodora, 725, Bom Retiro, 35160-215, Ipatinga, MG, Brasil. Correspondência para/Correspondence to: F.M. OLIVEIRA. E-mail:<flavia-marcia@uol.com.br>
} 


\section{Methods}

Female Swiss mice, 6-7 weeks old, were fed commercial diet alone or supplemented with either hybrid maize (1:1) or quality protein maize (1:1). Food intake, weight gain, abdominal obesity and plasma glucose, proteins, cholesterol and triglycerides levels were evaluated for 3 months.

\section{Results}

Dietary addition of the quality protein maize BR473 reduced food intake and abdominal fat, yet plasma glucose and triglycerides remained the same when compared with the addition of hybrid maize to the commercial feed.

\section{Conclusion}

A better dietary efficiency and the impacts on the biochemical parameters of the blood suggest that the quality protein maize BR473 is an important complement to guarantee dietary and nutritional security.

Indexing terms: food consumption; glucose; zea mays; triglycerides.

\section{N T R O D U Ç Ã O}

Na América Latina milhões de pessoas dependem do milho como fonte diária de alimento. Para muitos, esse cereal é a principal fonte de proteína da dieta. Essa cultura movimenta um mercado de, aproximadamente, US $\$ 40$ bilhões anuais que são distribuídos entre indústrias de produção de alimentos para consumo humano e animal'. Em 2005, o Brasil produziu mais de 35 milhões de toneladas de milho, distribuídos em 11 milhões de hectares².

A proteína do milho híbrido é considerada de baixa qualidade por ser deficiente em dois aminoácidos essenciais - lisina e triptofano ${ }^{3}$. Esses aminoácidos são considerados essenciais porque tanto o homem quanto outros monogástricos suínos, aves e camundongos - não conseguem sintetizá-los, tendo que obtê-los diretamente pela alimentação. Além disso, estudos mostram que a lisina e o triptofano exercem efeitos sobre o desenvolvimento de ratos ${ }^{4}$ e porcos ${ }^{5}$ que variam segundo a faixa etária dos animais.

A prevalência da desnutrição entre a população de baixa renda no Brasil e a política de segurança alimentar levaram à utilização de ingredientes alternativos como, por exemplo, produtos enriquecidos e multimisturas. A pesquisa agropecuária também vem desenvolvendo alimentos mais nutritivos, com baixo custo e de fácil produção, processamento e consumo, com o objetivo de reduzir os problemas da subnutrição .
O milho quality protein maize (QPM) representa uma variedade originalmente desenvolvida pelo Centro de Melhoramento de Milho e Trigo, no México, a partir do mutante opaco-2. Os pesquisadores do Centro Nacional de Pesquisas de Milho e Sorgo (Embrapa) vêm melhorando ainda mais as qualidades agronômicas e nutricionais do milho QPM ${ }^{3}$. Alguns estudos mostram que os valores de energia entre os milhos híbrido e QPM são semelhantes7, porém o milho QPM apresenta valores superiores de lisina e triptofano ${ }^{7,8}$.

A variedade do milho QPM BR 473 possui $0,9 \mathrm{~g}$ de triptofano e $4 \mathrm{~g}$ de lisina/ $\mathrm{kg}$ de grão contra $0,6 \mathrm{~g}$ e $2,6 \mathrm{~g} / \mathrm{kg}$ de grão do milho híbrido, respectivamente. Os produtos obtidos a partir dessa variedade, como fubás e rações experimentais, também apresentam valor protéico elevado ${ }^{6}$.

O maior teor de aminoácidos essenciais do milho QPM vem despertando interesse para o uso dessa variedade em estudos nutricionais de aves $^{3,9,10}$, suínos ${ }^{3,9,11-13}$, humanos ${ }^{14-16}$ e o cultivo em vários países em desenvolvimento ${ }^{17}$. Entretanto, ainda não se encontra um número significativo de resultados disponíveis na literatura, sendo que a maioria dos relatos, descreve parâmetros relacionados ao ganho de peso, consumo de ração, conversão alimentar e retenção de nitrogênio ${ }^{10-15,18}$.

Contudo, a análise isolada desses parâmetros não possibilita verificar a verdadeira ação da adição dietética de milho QPM, uma vez que 
os aminoácidos essenciais, presentes em níveis mais elevados nessa variedade, participam da estrutura primária de vários hormônios, neurotransmissores e proteínas do sistema imunológico que, por sua vez, estão envolvidos na regulação do metabolismo e de várias funções do organismo ${ }^{19}$.

Frente à qualidade protéica e à utilização do milho QPM para o consumo humano e animal, o objetivo deste estudo consistiu em avaliar os efeitos da adição dietética de milho QPM sobre aspectos bioquímicos e fisiológicos em camundongos.

\section{MÉ TO D O S}

Foram utilizados camundongos da linhagem Swiss, fêmeas, 6-7 semanas de idade, com peso médio de $30 \mathrm{~g}$, procedentes do biotério do Centro Universitário do Leste de Minas Gerais (Unileste MG). Todos os animais foram mantidos com livre acesso a água e dieta. Os procedimentos utilizados para experimentação animal foram realizados de acordo com as normas definidas pelo Colégio Brasileiro de Experimentação Animal (COBEA). Os grupos experimentais foram divididos e receberam dietas com ração comercial (RC), ração enriquecida com milho híbrido $(\mathrm{MH})$ e ração enriquecida com milho QPM (QPM), durante três meses, e possuíam em média 12 animais em cada um.

A ração comercial para camundongos foi triturada, peneirada e pesada, assim como os milhos híbrido e QPM. Foi realizada a adição de milho híbrido ou QPM à ração comercial na proporção de 1:1. Posteriormente, as rações $R C$, $\mathrm{MH}$ e QPM foram submetidas à formação pellets, sem aquecimento, com características similares. A quantidade de ração preparada foi equivalente ao consumo durante uma semana e a mesma foi acondicionada, em sacos plásticos hermeticamente fechados, e congelada. A composição química das rações está apresentada na Tabela 1.

Para avaliação do consumo da ração as sobras foram pesadas. É importante ressaltar que
Tabela 1. Composição química das rações (\%p/p).

\begin{tabular}{lrrr}
\hline & RC & MH & QPM \\
\hline Proteína & 9,03 & 10,49 & 9,64 \\
Gordura & 6,97 & 4,67 & 4,34 \\
Carboidratos & 64,76 & 67,69 & 64,83 \\
Cinzas & 5,33 & 5,84 & 5,67 \\
Fibra & 3,01 & 3,25 & 3,42 \\
Umidade & 10,90 & 8,06 & 12,10 \\
\hline
\end{tabular}

RC: Ração comercial; MH: ração comercial com adição de milho híbrido (1:1); QPM: ração comercial com adição de milho QPM (1:1).

todos os grupos receberam a mesma quantidade diária de ração. A apresentação dos resultados corresponde aos valores das médias das sobras das rações em gramas durante três meses, com os respectivos valores de desvio-padrão (DP).

Os animais foram pesados uma vez por semana com o auxílio de uma balança de precisão. A avaliação ponderal foi obtida pela diferença entre o peso atingido aos três meses após o início da dieta e o peso inicial.

Ao final do experimento, os camundongos foram anestesiados com tiopental sódico $(20 \mathrm{mg} / \mathrm{kg}$, via intraperitoneal), o retroperitôneo dos animais foi dissecado e explorado, permitindo que o tecido adiposo retroperitoneal fosse removido para posterior pesagem em prazo inferior a 5 minutos pós-morte ${ }^{20}$.

A fim de avaliar os parâmetros bioquímicos, $100 \mu \mathrm{L}$ de sangue foram coletados através da cauda dos animais, nos dias 30, 60 e 90 após o início da alteração da dieta, e centrifugados a 3000rpm, imediatamente após a coleta. Logo após a separação do soro, o material foi utilizado para realização dos testes. Para determinar os níveis de glicose, triglicerídeos e proteínas totais, foi colocado $1 \mathrm{~mL}$ de reagente enzimático em tubos de ensaio e, em cada tubo, foram adicionados, $10 \mu \mathrm{L}$ do padrão (KIT DOLES) ou $10 \mu \mathrm{L}$ das amostras de soro. Um tubo contendo apenas o reagente enzimático foi utilizado como controle branco. Após 10 minutos de incubação, em temperatura ambiente, a leitura da absorbância foi realizada em espectrofotômetro utilizando um comprimento de onda igual a 500,510,550nm, respecti- 
vamente. Para determinar os níveis de colesterol, foram colocados $2 \mathrm{~mL}$ de reagente enzimático em tubos de ensaio e, em cada tubo, foram adicionados $20 \mu \mathrm{L}$ do padrão (KIT DOLES) ou $20 \mu \mathrm{L}$ das amostras de soro. Um tubo contendo apenas o reagente enzimático foi utilizado como controle branco. Após 5 minutos de incubação, em temperatura ambiente, a leitura da absorbância foi realizada em espectrofotômetro utilizando um comprimento de onda igual a 510nm. É importante ressaltar que os animais foram privados de ração 6 horas antes da coleta das amostras.

Os resultados obtidos foram analisados por análise de variância (ANOVA) utilizando-se o programa GraphPad Prism 4. Foi estabelecido um nível de significância de 5\%. Em alguns experimentos optou-se em demonstrar a existência de diferenças com significância estatística entre os grupos e/ou coletas pelo uso de letras distintas $(a, b, c)$.

\section{RESULTADOS}

A alteração na composição da ração, devido à adição de milho, pode resultar em modificações no padrão de saciedade e fome, induzindo menor ou maior consumo da mesma pelos animais. Dessa maneira, o acompanhamento diário do consumo de ração permitiu observar que a ingestão foi menor no grupo QPM, uma vez que o peso das sobras do alimento foi maior em relação aos grupos $\mathrm{RC} e$ $\mathrm{MH}\left(\right.$ Sobras $_{(\mathrm{QPM})}=41,44, \mathrm{DP}=12,57 \mathrm{~g}$; Sobras $_{(\mathrm{RC})}=14,15$, $\mathrm{DP}=13,09 \mathrm{~g}$; Sobras ${ }_{(\mathrm{MH})}=7,59, \mathrm{DP}=10,06 \mathrm{~g} / \mathrm{p}_{(\mathrm{QPM} / \mathrm{RC})}$ $<0,01$ e $\left.p_{(\mathrm{QPM} / \mathrm{MH})}<0,01\right)$.

O ganho de peso significativo, em todos os grupos, ocorreu a partir da $10^{a}$ semana após o início da alteração da dieta. No entanto, não houve diferença significante no ganho de peso entre os grupos (Ganho de Peso ${ }_{(\mathrm{QPM})}=22,40$ $\mathrm{DP}=8,69 \mathrm{~g}$; Ganho de $\mathrm{PesO}_{(\mathrm{RC})}=20,77 \mathrm{DP}=5,96 \mathrm{~g}$; Ganho de Peso $\left._{(\mathrm{MH})}=23,17 \mathrm{DP}=7,14 \mathrm{~g}\right)$. Os animais tratados com a ração QPM e comercial RC apresentaram um menor acúmulo de tecido adiposo em relação aos animais alimentados com a ração $\mathrm{MH}$ (Figura 1).
Além disso, foi avaliada se a adição dos milhos híbrido e QPM na ração comercial interferiu nos parâmetros bioquímicos do sangue, uma vez que foram observadas alterações no padrão de consumo alimentar e na gordura retroperitoneal.

Foi possível observar que houve elevação dos triglicerídeos plasmáticos dos animais ali-

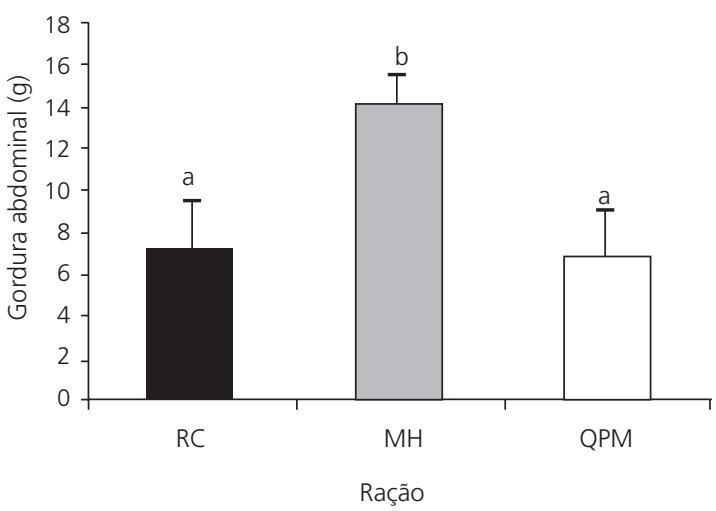

Figura 1. Peso do tecido adiposo retroperitoneal de camundongos alimentados com ração comercial (RC), ração comercial e milho híbrido $(\mathrm{MH})$ e ração comercial e milho de alta qualidade protéica (QPM). ( $n=12$; número de repetições $=2 ; a / b \quad p<0,01)$.

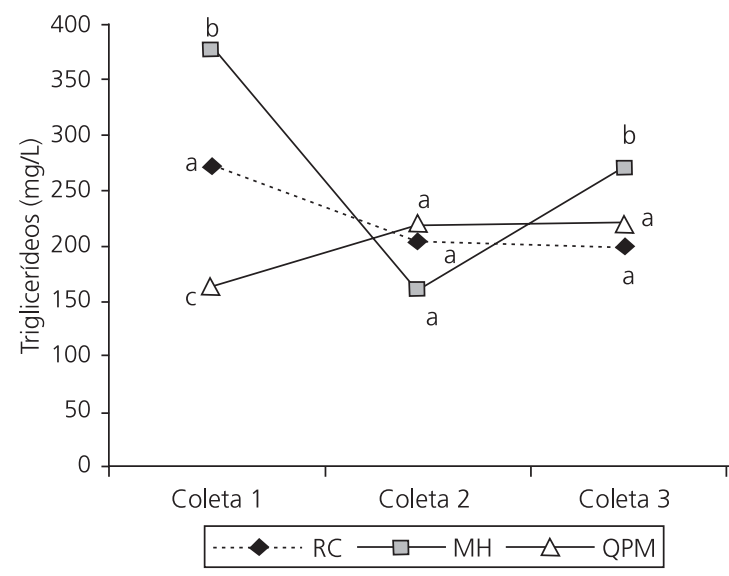

Figura 2. Valores de triglicerídeos plasmáticos de camundongos alimentados com ração comercial (RC), ração comercial com milho híbrido $(\mathrm{MH})$ e ração comercial suplementada com milho de alta qualidade protéica (QPM). A coleta das amostras foi realizada 30 dias (Coleta 1), 60 dias (Coleta 2) e 90 dias (Coleta 3) após o início do experimento $(n=12$; número de repetições $=2 ; a / b / c p<0,05)$. 
mentados com ração QPM, 60 dias após o início do experimento, cujos valores, posteriormente, mantiveram-se constantes, quando comparados aos do grupo que recebeu ração comercial RC. No entanto, aos 90 dias, os valores de triglicerídeos desses animais foram inferiores aos do grupo $\mathrm{MH}$ (Figura 2). Apesar da elevação dos triglicerídeos,

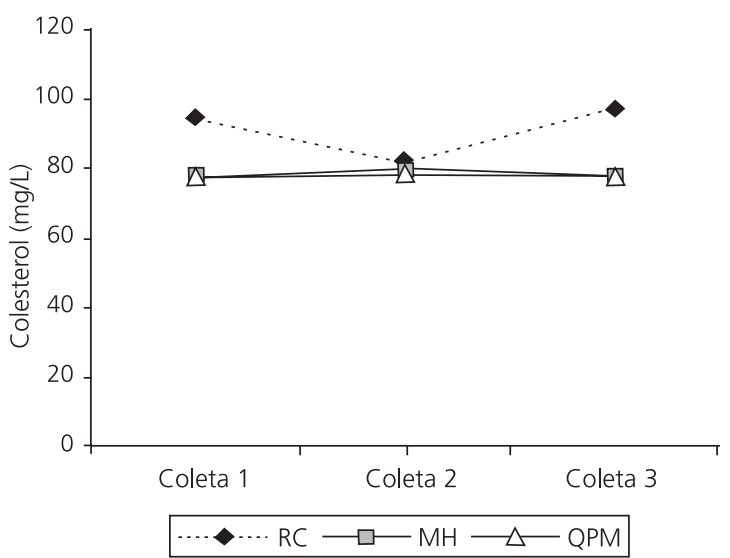

Figura 3. Valores de colesterol plasmático de camundongos alimentados com ração comercial (RC), ração comercial com milho híbrido $(\mathrm{MH})$ e ração comercial com milho de alta qualidade protéica (QPM). A coleta das amostras foi realizada 30 dias (Coleta 1), 60 dias (Coleta 2) e 90 dias (Coleta 3) após o início do experimento ( $n=12$; número de repetições $=2$; não houve diferença significante entre os grupos)

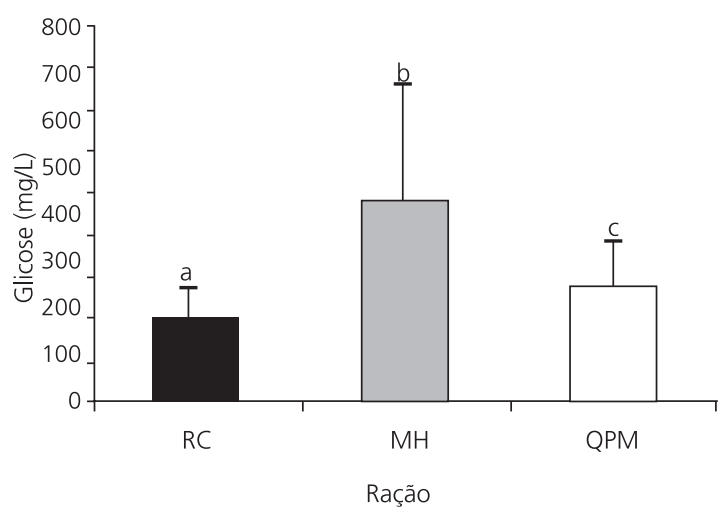

Figura 4. Valores de glicose sangüínea de camundongos alimentados com ração comercial (RC), ração comercial com milho híbrido $(\mathrm{MH})$ e ração comercial com milho de alta qualidade protéica (QPM). A coleta das amostras foi realizada 90 dias após o início do experimento $(n=12$; número de repetições $=2 ; a / b \quad p<0,05)$. todos os grupos apresentaram os valores de colesterol constantes e similares (Figura 3). Os valores de proteínas plasmáticas também não foram diferentes entre os grupos e ao longo do experimento (dados não mostrados).

Em relação à concentração de glicose plasmática foi possível observar que o tratamento com milho QPM não interferiu na glicemia, ao ser comparado à ração comercial RC. Por outro lado, a utilização do milho híbrido $\mathrm{MH}$ induziu ao aumento nos valores de glicose sangüínea (Figura 4).

\section{I S C U S S Ã O}

Os resultados aqui apresentados mostram que, de modo geral, a adição de milho QPM ou híbrido nas rações comerciais resultou em alterações no consumo alimentar, no ganho de gordura retroperitoenal, bem como em alguns parâmetros bioquímicos do sangue.

A adição de milho QPM à ração comercial reduziu o consumo alimentar por camundongos, ao ser comparada ao consumo das rações comerciais enriquecidas ou não com milho híbrido. O consumo menor pode estar relacionado ao aumento de conteúdo de triptofano nessa variedade de milho. A saciedade é induzida por vários estímulos após a ingestão, entre eles, distensão gástrica, liberação de peptídeos, elevação da glicose e de aminoácidos no sangue e elevação da serotonina ${ }^{21,22}$ que, por sua vez, está diretamente relacionada à concentração de triptofano.

Apesar do menor consumo de ração pelos animais do grupo QPM, o ganho de peso foi igual em relação aos demais grupos, sugerindo, dessa maneira, uma melhor eficiência alimentar. A superioridade do milho QPM também foi evidenciada em estudos que constataram melhores performances de crescimento de suínos ${ }^{11,12}$, frangos de corte $^{10}$ e crianças ${ }^{7,16}$. Além disso, a avaliação de indicadores nutricionais permitiu observar que a adição de milho QPM à ração de ratos aumentou a utilização e a eficiência protéica ${ }^{23}$. O acompanhamento de duas gerações de ratos mostrou que o consumo de tortillas enriquecidas com milho 
QPM não só promoveu um maior crescimento dos animais como também aumentou a taxa de fecundidade, o número de nascidos vivos e a taxa de sobrevivência neonatal na segunda geração ${ }^{24}$.

É importante ressaltar que o ganho de peso apresentado pelos animais tratados com ração comercial e milho QPM não foi associado ao ganho de tecido adiposo retroperitoneal. Por outro lado, os camundongos que receberam ração com milho híbrido apresentaram um aumento significante de gordura retroperitoneal, que pode estar relacionado à elevação de glicose sangüínea e ao maior consumo de ração apresentado pelos mesmos. Vários estudos mostram que a elevação dos níveis glicêmicos contribui, principalmente, para o desenvolvimento da obesidade abdominal e da resistência à insulina ${ }^{25-27}$. Além disso, como se fosse um ciclo vicioso, o maior percentual de gordura corporal resulta em pior controle glicêmico na maioria dos indivíduos ${ }^{28}$.

O aumento do percentual de gordura abdominal, incluindo a retroperitoneal, constitui um fator de risco para o desenvolvimento de hiperlipidemias e distúrbios cardiovasculares ${ }^{29}$. Esses dados corroboram o aumento dos níveis de triglicerídeos nos animais alimentados com ração enriquecida com milho híbrido.

Ao contrário dos resultados referentes aos efeitos da adição de milho híbrido na ração comercial, a utilização da variedade do milho QPM não modificou a concentração de triglicerídeos e glicose. No entanto, os valores dos demais parâmetros bioquímicos, como, proteínas e colesterol, não foram diferentes entre os grupos. Em concordância com os resultados apresentados, um estudo demonstrou que a utilização de rações compostas de milho QPM e ingredientes nutricionais alternativos, como, por exemplo, farinha de soja, aveia, banana e açúcar mascavo em ratos, não interferiu nos valores sangüíneos de colesterol, glicose e proteínas totais permanecendo, inclusive, dentro da faixa normalidade ${ }^{23}$.

Além disso, outros estudos vêm demonstrando aspectos importantes relacionados à utilização dessa variedade, como, por exemplo, baixo custo, boa aceitabilidade, eficiência protéica ${ }^{10-13}$ e recuperação de crianças desnutridas ${ }^{14,16}$.

\section{O N CLUS Ã O}

A adição dietética de milho QPM, ao contrário do milho híbrido, resulta na modificação de parâmetros corporais e bioquímicos do sangue que, aparentemente, contribuem para redução do consumo alimentar e manutenção dos níveis de triglicerídeos e glicose.

A melhor eficiência alimentar e os impactos sobre os parâmetros bioquímicos do sangue sugerem o potencial do uso do milho QPM BR473 como um importante complemento para garantir a segurança alimentar e nutricional.

\section{COLABORADORES}

A.C. SILVA e D.K. BRAGA participaram na elaboração de estratégia experimental, coleta de dados, tabulação e discussão dos resultados e elaboração do artigo. R.F. MURADAS participou na coleta de dados, tabulação e discussão dos resultados e elaboração do artigo. E.G. FERREIRA participou na elaboração de estratégia experimental, tabulação e discussão dos resultados e elaboração do artigo. F.M. OLIVEIRA e A.S.V. COSTA participaram na elaboração do projeto de pesquisa, tabulação e discussão dos resultados e elaboração do artigo.

\section{REFERÊ NCIAS}

1. Carneiro AA, Carneiro NP, Carvalho CHS, Vasconcelos MJV, Paiva E, Lopes MA. Milho transgênico. Biotecnol. 2001;15(3):10-8.

2. Instituto Brasileiro de Geografia e Estatística. Produção agrícola municipal 2005 - Cereais, leguminosas e oleaginosas [comunicação social] 2006 [citado 30 jun 2006]. Disponível em: http:// www.ibge.gov.br/home/presidencia/noticias/ noticia_visualiza.php?id_noticia=635\&id_pagina $=1$

3. Peixoto MJVVD, Parentoni SN, Gama EEG, Magnavaca R, Paiva E, Rego MM. Perspectiva de utilização de milhos de alta qualidade protéica no Brasil. Informe Agropecuário. 1990; 14:23-34. 
4. Gahl MJ, Finke MD, Crenshaw TD, Benevenga NJ. Use of a four-parameter logistic equation to evaluate the response of growing rats to ten levels of each indispensable amino acid. J Nutr. 1991; 121(11):1720-9.

5. Fuller MF, McWilliam R, Wang TC, Giles LR. The optimum dietary amino acid pattern for growing pigs; requirements for maintenance and for tissue protein accretion. Br J Nutr. 1990; 62(2):255-67.

6. Guimarães PEO, Pacheco CAP, Paes MDC, Santos MX, Parentoni SN, Gomes e Gamas EE, et al. BR 473: variedade de milho amarela com qualidade protéica melhorada (QPM). Brasil: Ministério da Agricultura, Pecuária e Abastecimento; 2004. p.1-4.

7. Hoisington D. Opportunities for nutritionally enhanced maize and wheat varieties to combat protein and micronutrient malnutrition. Food Nutr Bull. 2002; 23(4):376-777.

8. Paes MCD. Perspectivas nutricionais do milho de alta qualidade protéica. Óleos e Grãos. 1995; 24(2):49-95.

9. Rostagno HS, Silva DJ, Costa PMA, Fonseca JB, Pereira JAA, Soares PR, et al. Composição de alimentos e exigências nutricionais de aves e suínos [tabelas brasileiras]. Viçosa: UFV; 1992.

10. Jarquin R, Albertazzi C, Bressani R. Value of Opaque-2 corn protein for chicks. J Agricult Food Chem. 1970; 18(1):268-72.

11. Sullivan JS, Knabe DA, Bockholt AJ, Gregg EJ. Nutritional value of quality protein maize and food corn for starter and growth pigs. J Anim Sci. 1989; 67(5):1285-9.

12. Burgoon KG, Hansen JA, Knabe DA, Bockhold AJ. Nutritional value of quality protein maize starter and finisher swine. J Anim Sci. 1992; 70(3):811-7.

13. Gomez MH, Serna-Saldivar SO, Corujo Jl, Bockholt AJ, Rooney LW. Wet milling proteins of quality protein maize and regular corns. In: Mertz ET, editor. Quality protein maize. St Paul: American Association of Ceral Chemists; 1992. p.239-60.

14. Graham GG, Lembcke J, Morales E. Quality-protein maize as the sole source of dietary protein and fat for rapidly growing young children. Pediatrics. 1990; 85(1):85-91.

15. Graham GG. Quality-protein maize with a high fat content as a weaning food. J Ped Gastroenterol. 1993(2); 17:139-44.

16. Pradilla AG, Harpstead DD, Sarria A, Linares FA, Francis CA. Quality protein maize in human nutrition. In: High: quality protein maize. Stroudsburg Penn. Doedwn: Hutchinson \& Ross; 1975. p.27-37.

17. Gibbon BC, Larkins BA. Molecular genetic approach to developing quality protein maize. Trends Genet. 2005; 21(4):227-33.
18. Glória ECS, Almeida NAV, Costa ASV, Henriques Júnior E, Martins SL, Paula H, et al. Avaliação protéica de uma nova multimistura com base no milho QPM BR 473. Rev Nutr. 2004; 17(3):379-85.

19. Ferreira RR, Varisi VA, Meinardt LW, Lea PJ, Azevedo RA. Are high-lysine ceral crops still a chanllenge? Braz J Med Biol Res. 2005; 38(7):985-94.

20. Figueiró-Filho EA, Duarte G, El Beitune P, Quintana SM, Marcolin AC. Efeito diabetogênico das drogas anti-retrovirais em ratas Wistar prenhes. RBGO. 2004; 26(1):31-6

21. Aguilera A, Selgas R, Codoceo R, Bajo A. Uremic anorexia: a consequence of persistently high brain serotonin levels? The tryptophan/serotonin disorder hypothesis. Perit Dial Int. 2000; 20(6): 810-6.

22. Sato T, Laviano A, Megui MM, Chen C, Rossi-Fanelli F, Hatakeyama K. Involvement of plasma leptin, insulin and free tryptophan in cytokine-induced anorexia. Clin Nutr. 2003; 22(2):139-46.

23. Paula $H$, Santos RC, Silva ME, Glória ECS, Pedrosa $\mathrm{ML}$, Almeida NAV, et al. Biological evaluation of a nutritional supplement prepared with QPM Maize Cultivar BR 473 and other traditional food items. Braz Arch Biol Tecnol. 2004; 47(2): 247-51.

24. Amaya-Gueera CA, Alanis-Gusman MG, Serna Saldivar SO. Effects of soybean fortification on protein quality of tortilla based diets produced from regular and quality protein maize. Plant Foods Hum Nutr. 2004; 59(2):45-50.

25. LaHaye SA, Hollet PM, Vyselaar JR, Shalchi M, Lahey KA, Day AG. Comparison between a low glycemic load diet and a Canada Food Guide diet in cardiac rehabilitation patients in Ontario. Can J Cardiol. 2005; 21(6):489-94.

26. Layman DK. The role of leucine in weight loss diets and glucose homeostasis. J Nutr. 2003; 133(1): 261S-7S.

27. Lopes HF. Síndrome metabólica: importância do tecido adiposo e dos ácidos graxos livres. Rev Soc Cardiol Estado de São Paulo. 2004;14(4):567-73.

28. Corrêa FHS, Taboada GF, Júnior CRMA, Faria AM, Clemente ELS, Fuks AG, et al. Influência da gordura corporal no controle clínico e metabólico de pacientes com diabetes mellitus Tipo 2. Arq Bras Endocrinol Metab. 2003; 47(1):62-8.

29. Ávila ALV. Tratamento não farmacológico da síndrome metabólica: abordagem do nutricionista. Rev Soc Cardiol Estado de São Paulo. 2004; 14(4):652-8.

Recebido em: 15/2/2006

Versão final reapresentada em: 30/10/2006 Aprovado em: 3/1/2007 
